\title{
REDUCING ENVIRONMENTAL NOISE IN THE MOTORCYCLE TEST SECTOR
}

\author{
João Cláudio Ferreira Soares ${ }^{1}$ and Rebeca Pereira Soares ${ }^{2}$
}

${ }^{1,2}$ Research and Innovation Analysis Center Foundation - FUCAPI, Manaus - Amazonas, Brazil.

Email: claudio.ueabm@gmail.com, rebecapsoares01@gmail.com

Received: May 08 ${ }^{\text {th }}, 2020$

Accepted: Jun $15^{\text {th }}, 2020$

Published: June $30^{\text {th }}, 2020$

Copyright (C2016 by authors and Galileo Institute of Technology and Education of the Amazon (ITEGAM).

This work is licensed under the Creative Commons Attribution International License (CC BY 4.0).

https://creativecommons.org/licen ses/by/4.0/

\begin{abstract}
The noise pollution is currently the third biggest environmental problem, affecting many people. When exposed to a high level of noise, the people can show occupational, social, physical and/or psychological problems. The noise is part of people's daily lives and work environments, so research projects and proposals that aim to improve this difficult reality are justified. Personal protection is an immediate measure. However, the control should aim mainly at the emitting source, whether in the noise generation mechanism or in the containment of the propagation. The general objective of this work is the developing of an acoustic booth proposal to reduce environmental noise from the motorcycle test area. The specific objectives are: to map the environmental noise level in the motorcycle testing area; propose an acoustic booth design. In the methodology sought practical results oriented to the problem of controlling environmental noise at the emitting source. An inductive approach is chosen when collecting noise data in the test sector and developing a design as a result of analysing that data. An exploratory, descriptive and explanatory study was developed. Exploratory in data collection, descriptive and explanatory in the development of the acoustic cabin. The investigation strategy uses a case study focused on specifying all qualitative aspects that allow the total reproduction of the results. So, the sound sources that generate noise from the motorcycle test area were verified; area noise levels were measured; the area with the highest noise level was evaluated; the place of installation of the cabin was evaluated; the noise absorbing material was defined; each item used to make the cabin was listed; the costs for making the cabin were defined; the way the panels were assembled was defined; and; The final design of the acoustic booth was designed. The highest noise level found was the motorcycle horn, which when performing the functional test reached an average of $100.91 \mathrm{~dB}$. With the implementation of acoustic booth in the test area, it is proposed to reduce environmental noise in the areas of people circulation.
\end{abstract}

Keywords: Sounds, Noises, Acoustic Booth.

\section{INTRODUCTION}

Sound is part of our daily lives and can come in many forms; noise is a type of sound, but unpleasant. The noise pollution is currently the third biggest environmental problem, affecting many people, because when exposed to a high level of noise it can cause, in addition to occupational problems, social problems, physical and/or psychological [1,2].

The main sources of noise and noise pollution from large cities and environments are motor vehicles $[3,4]$. Which leads us to study solutions to reduce the noise level in a motorcycle test environment, since the tests performed generate high noise levels.
The general objective of this research is to develop an acoustic booth to reduce the environmental noise in the test area of a motorcycle manufacturer.

The specific objectives are: to map the level of environmental noise in the motorcycle testing area; and propose an acoustic booth project.

The methodology sought practical results oriented to the problem. An inductive approach is chosen when collecting data and developing a project as a result of data analysis. In the nature of the investigation, an exploratory, descriptive and explanatory study is combined. Exploratory in data collection, descriptive and explanatory in the development of the proposed solution to the 
problem. The investigation strategy uses a case study focused on qualitative aspects $[5,6]$.

Initially, the work presents a literature review that addresses the main concepts related to noise, its effects and necessary controls. Then he develops a case study carried out in a motorcycle industry. It presents the technical aspects of the collection of environmental noise in a test sector and concluded with the elaboration of an acoustic cabin project.

\section{LITERATURE REVIEW}

\section{II.1 SOUND PRESSURE}

Sound is a form of energy transmitted by the collision of molecules, there is no permanent displacement, that is, there is no transfer of matter, only energy, sound is, therefore, a form of energy that flows through elastic means $[7,8]$.

The sound pressure wave is the disturbance that occurs in the environment, where the sound vibration movement was transmitted from particle to particle without the migration of particles as shown in Figure $1[8,9]$.

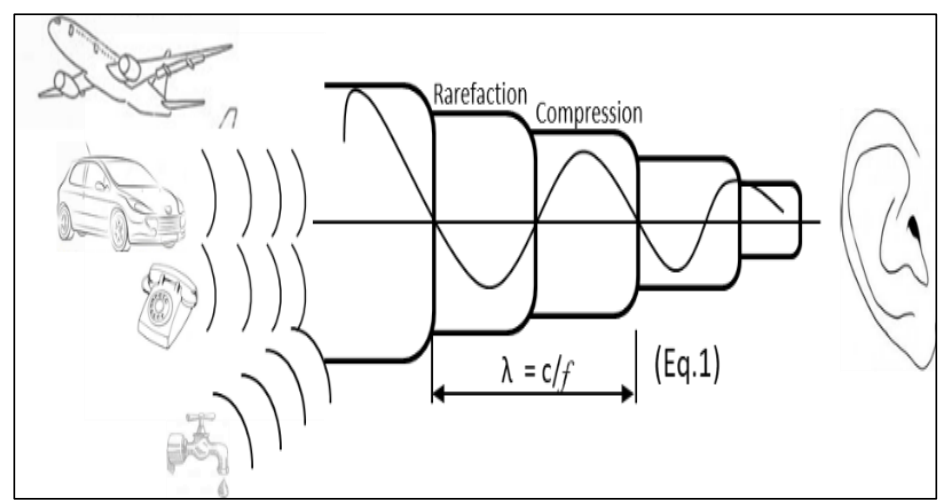

Figure 1: Propagation of sound waves.

Source: [10].

The wavelength and the speed of sound propagation are two factors that need to be taken into account the temperature and the medium, where the wavelength is represented by Equation 1, being the ratio between the speed of sound and the frequency in a time interval [9].

Nepomuceno [11] characterizes the propagation of sound through waves, depending on the medium and the temperature.

These waves that propagate, in a given instant, are repeated in different places with a lag equivalent to the necessary time of the travel of a wave, with the speed of sound $[8,9]$.

The speed of sound is according to Equation 2 [9] and Table 1 shows the comparison of the speed of sound in different materials [11].

Wavelength:

$$
\lambda=\frac{c}{f}
$$

Speed of sound:

$$
c=\lambda f
$$

Where:

$\lambda=$ Wavelength in meters $(\mathrm{m})$

$\mathrm{c}=$ Speed of sound in meters per second $(\mathrm{m} / \mathrm{s})$

$\mathrm{f}=$ Frequency over a given time interval in hertz $(\mathrm{Hz})$
Table 1: Speed of sound in different materials.

\begin{tabular}{|c|c|c|c|}
\hline MATERIAL & $\begin{array}{c}\text { PHYSICAL } \\
\text { STATE }\end{array}$ & TEMPERATURE & VELOCITY \\
\hline AIR & GASEOUS & $20^{\circ} \mathrm{C}$ & $340 \mathrm{~m} / \mathrm{s}$ \\
\hline HYDROGEN & GASEOUS & $20^{\circ} \mathrm{C}$ & $1.261 \mathrm{~m} / \mathrm{s}$ \\
\hline WATER & LIQUID & $20^{\circ} \mathrm{C}$ & $1.500 \mathrm{~m} / \mathrm{s}$ \\
\hline STEEL & SOLID & $20^{\circ} \mathrm{C}$ & $5.100 \mathrm{~m} / \mathrm{s}$ \\
\hline
\end{tabular}

Source: [11].

\section{II.2 SOUND INTENSITY, INTENSITY LEVEL AND SOUND PRESSURE}

The sound quality is related to the energy carried by the wave, the energy intensity of the sound is the quotient of the power emitted by the source, by the area where the sound is found, as shown in Equation 3 [9]:

Energy intensity:

$$
I=\frac{P}{S}
$$

Where:

$\mathrm{I}=$ Energy intensity (physical) in watts per square meter $(\mathrm{W} / \mathrm{m} 2)$

$\mathrm{P}=$ Sound source power in watts $(\mathrm{W})$

$\mathrm{S}=$ Area where sound is found instantly in square meters (m2)

Defines the intensity of sound energy as the average amount of energy that crosses an area perpendicular to the direction of propagation of the wave, in a certain unit of time [9].

Explains that the level of intensity and sound pressure are obtained through Equations 4 and 5, respectively [12].

Sound Intensity Level:

$$
N I=10 \log \frac{I}{I_{0}}
$$

Sound Pressure Level:

$$
N P S=10 \log \frac{P^{2}}{P_{0}^{2}}=20 \log \frac{P}{P_{0}}
$$

Where:

$\mathrm{I}=\mathrm{It}$ is the acoustic intensity in Watt $/ \mathrm{m} 2$.

Io $=$ It is the reference intensity $=10-2 \mathrm{Watt} / \mathrm{m} 2$.

$\mathrm{P}=\mathrm{It}$ is the sound pressure in $\mathrm{N} / \mathrm{m} 2$.

$\mathrm{Po}=\mathrm{It}$ is the reference value of the hearing threshold in $\mathrm{N} / \mathrm{m} 2, \mathrm{P} 0$ $=\sqrt{ }(\rho \mathrm{I} 0 \mathrm{c})=\sqrt{ }(415 \times 10-12$, that results in $0,00002 \mathrm{~N} / \mathrm{m} 2$.

Informs that the unit to express the level of intensity or sound pressure is the decibel $(\mathrm{dB})$, this unit was first used due to the loss of power in the telephone cables, but it was also observed that $1 \mathrm{~dB}$ corresponded to the minimum variation audible sound [9].

\section{II.3 ABSORPTION COEFFICIENT}

The absorption coefficient as the ratio between the absorbed energy and the incident energy, shown in Equation 6 [9]. The energy produced by a sound source is called incident energy, when reaching an obstacle, part of the energy is reflected, transmitted or absorbed as shown in Figure $3[8,9,13]$.

Absorption coefficient:

Where:

$$
\alpha=\frac{W_{\mathrm{a}}}{W_{\mathrm{i}}}
$$


$\mathrm{W}_{\mathrm{a}}=$ Energy absorbed $\left(\mathrm{W} / \mathrm{m}^{2}\right)$

$\mathrm{W}_{\mathrm{i}}=$ Energy incident $\left(\mathrm{W} / \mathrm{m}^{2}\right)$

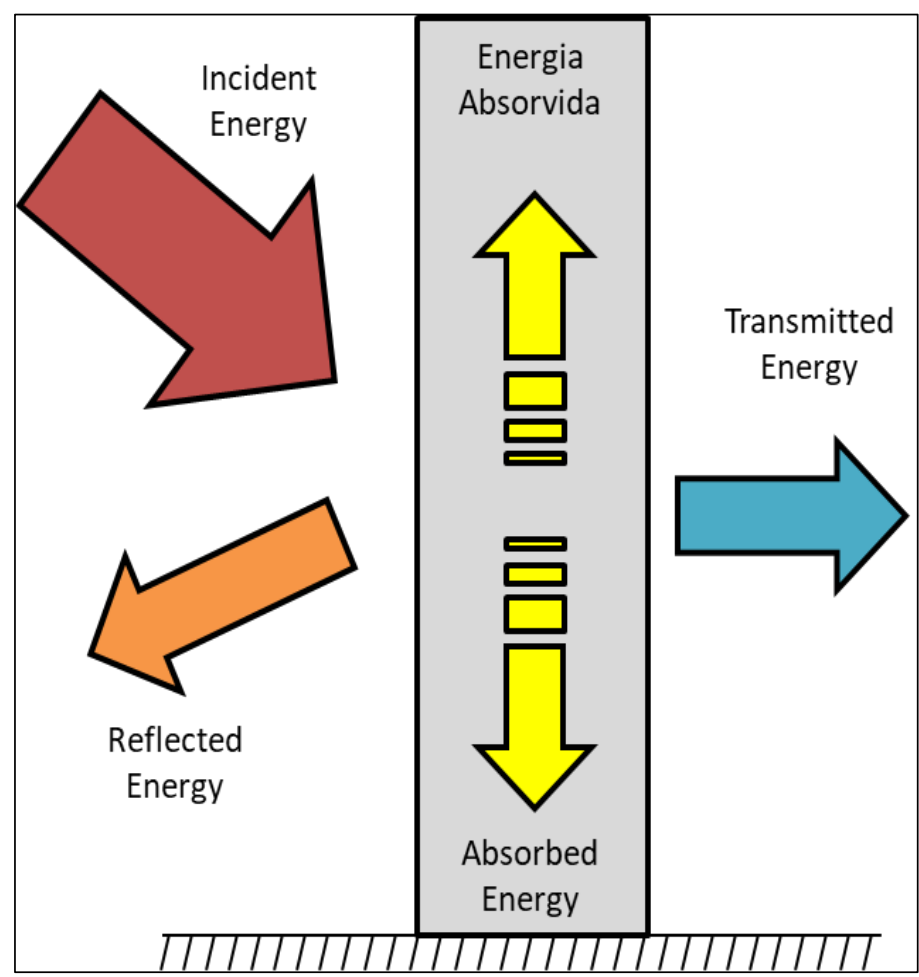

Figure 3: Incident energy behavior. Source: [9].

\section{II.4 NOISE EFFECT}

The human ear is the best sound sensor there is. Prolonged exposure to a high level of noise causes deterioration of the auditory system, so it is important to understand the functioning and loss mechanism of this system [10].

It is customary to divide the effects of noise on men in two parts: those that affect people's health and well-being and the effects on hearing $[1,2,4,14]$.

The hearing threshold, ie, where it is possible to detect sound pressure by the human ear is $20 \times 10^{-6} \mathrm{~N} / \mathrm{m}^{2}$ at a frequency of $1 \mathrm{kHz}$ and the range, or full frequency band audible to humans, is $20 \mathrm{~Hz}$ at $20 \mathrm{kHz}$, taking into account that the auditory sensitivity is not the same in the whole range $[8,10]$.

According to [10] any reduction in sensitivity is considered hearing loss, the first frequency range that you lose is 4 to $6 \mathrm{kHz}$, and usually accompanies the sensation of noise perception after the noise field is removed, and more critically the nerve cells inner ear are damaged by losing hearing (deafness).

Other effects can be associated with exposure to loud noises, [12] states that this exposure can cause on man: pupil dilation, increased production of thyroid hormone, increased heart rate; increased production of adrenaline and corticotrophin, contraction of the stomach, muscle reaction, contraction of blood vessels; and are shown by some behaviors, such as: nervousness; mental fatigue; frustration; low job performance; irritability; social conflicts $[1,2]$.

The exposure to occupational noise is one of the biggest problems for employees, causing these non-auditory problems [3].

\section{II.5 NOISE CONTROL}

Noise is a sound characterized by a large number of acoustic vibrations, with amplitudes and phases, distributed at random $[8,13]$. Describes the noise intensities in a sequence from the inaudible to the one that causes auricular pain, according [3] to Table 2.

Table 2: Auditory sensations and sound sources.

\begin{tabular}{|c|c|c|}
\hline Sensation & Noise source & Intensity (dB) \\
\hline \multirow{3}{*}{$\begin{array}{c}\text { Ear pain/hearing } \\
\text { damage }\end{array}$} & Rocket taking off & 200 \\
\cline { 2 - 3 } & Rifle Shot & 150 \\
\cline { 2 - 3 } & Airplane taking off close & 140 \\
\cline { 2 - 3 } & Airplane taking off - 30m & 130 \\
\hline Uncomfortable & Police siren & 110 \\
\hline Very intense & Motorcycle & 90 \\
\hline \multirow{2}{*}{ Intense } & Vacuum Cleaner & 70 \\
\cline { 2 - 3 } & Normal conversation & 60 \\
\hline \multirow{2}{*}{ Audible } & Peaceful office & 50 \\
\cline { 2 - 3 } & Leggy & 40 \\
\hline Silent & Library interior & 30 \\
\hline Very silent & Whisper & 20 \\
\hline Inaudible & Silence & 0 \\
\hline
\end{tabular}

Source: [3].

The NR 15 [15], classifies noise into three types: 1) Continuous noises: variation in the level of sound intensity very small as a function of time (longer than 1 second); 2) Floating noises: large variations in level as a function of time; 3) Impulsive or impact noises: they present high levels of sound intensity, in a very short time (less than 1 second), which are those caused by explosions and impacts.

According to [9], in cases where noise problems were not addressed in the design phase, the control will be performed on the sound transmission path between the source and the receiver. The author lists some control methods: increasing the distance between the source and the receiver; isolation of machines, that is, confinement; installation of silencers; and/or surface treatment with sound absorbent materials [16,17].

\section{II.6 NOISE ABSORPTION MATERIALS}

As explained by [9], the waves of sound or noise, when indoors, suffer interference from other waves that are reflected by the wall, floor or ceiling. Part of the sound energy, according to the author, is reflected, another part disappears behind the surface, which are the sound energy dissipated and the sound energy transmitted.

According to [10], the materials used for noise control are:

- Sound absorbing materials (resistive mechanism): A part of the acoustic energy is transformed into thermal energy, this is due to the viscosity of the air $[16,17]$. the device.

- Reactive device: acoustic energy generates resonance in

- Active device: the noise field is canceled by another field at $180^{\circ}$ of lag.

High-sound-absorbing materials are usually porous and/or fibrous, says [12]. Nepomuceno [11] clarifies that absorption is a function of frequency and porosity, acting through viscous friction and absorbs up to $100 \%$ of the incident energy [16,17].

In porous materials, acoustic energy enters the pores, dissipating through multiple reflections and viscous friction, transforming into thermal energy, as shown in Figure $4[10,13]$, $[16,17]$. 


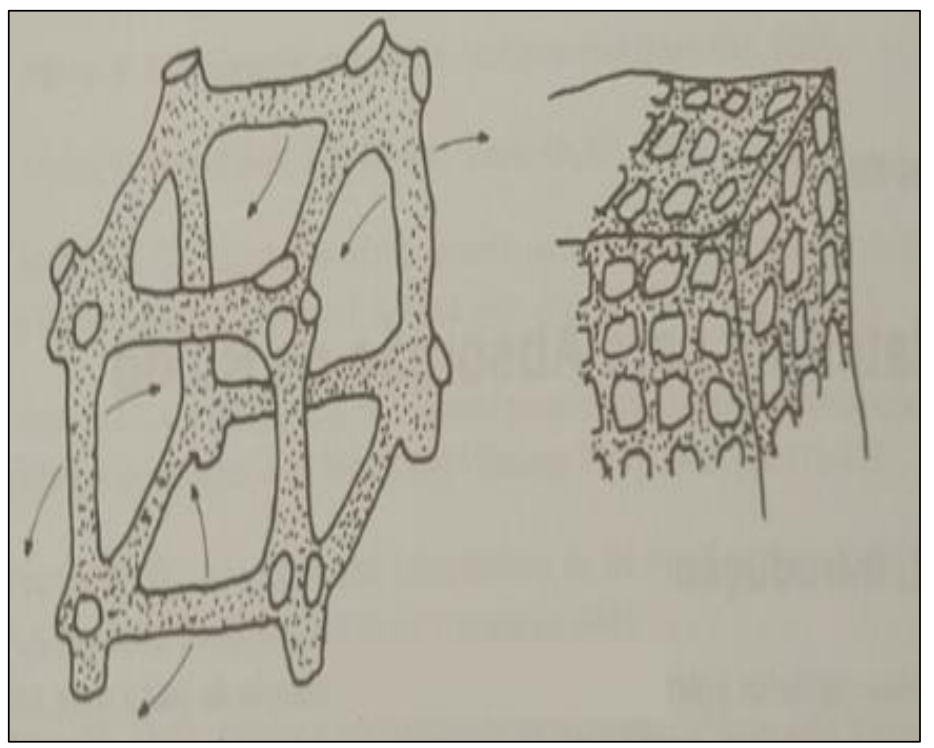

Figure 4: Porous material.

Source: [10].

In fibrous materials, the acoustic energy passes between the fibers, causing them to vibrate together with the air and is transformed into thermal energy by friction when it dissipates, as shown in Figure 5 [10] [13], [16], [17].

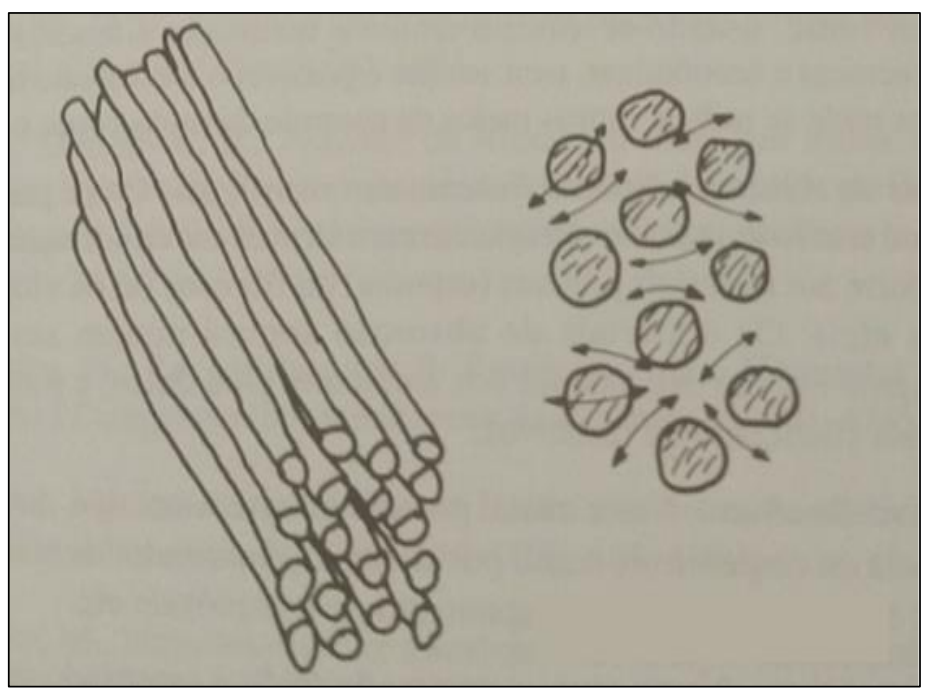

Figure 5: Fibrous material.

Source: [10].

According to [10] for all material used in sound absorption, it is necessary to admit the passage of an air flow, which will allow the propagation of acoustic waves. In addition, the author lists the characteristics necessary for choosing this material: Absorption coefficient $[\alpha=W a / W i$ (Equation 6), ratio between the absorbed and incident energy]; Noise frequency; High temperature characteristics; Weight and volume in relation to the available space; Fixing and maintenance; Appearance and painting; and Cost.

According to [10] the three most used types of materials for sound absorption are:

Polymer foam, shown in Figure 6, characterized by open pores, great for air flow, without erosion, but the risk of contamination with oils and other impurities tends to block the orifices, as they are flammable, additives are used that worsen the mechanical characteristics and its useful life, works in the temperature range of $-40^{\circ} \mathrm{C}$ to $100^{\circ} \mathrm{C}[10]$.

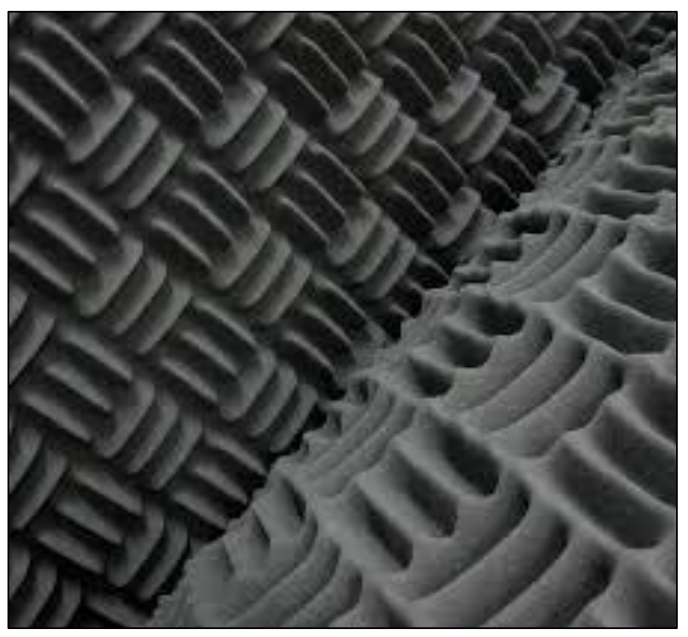

Figure 6: Polyurethane foam.

Source: [10].

Glass wool, shown in Figure 7, for this case the author informs that it is available for use in many forms, such as panels, blankets, felts, cords or applied by blasting. To improve resistance to vibrations and fluid flow, resin is usually applied to seal, but the sealing makes the material become combustible, without the resin the glass wool resists up to $450^{\circ} \mathrm{C}$, using a flame retardant additive. resist up to $540^{\circ} \mathrm{C}[10]$.

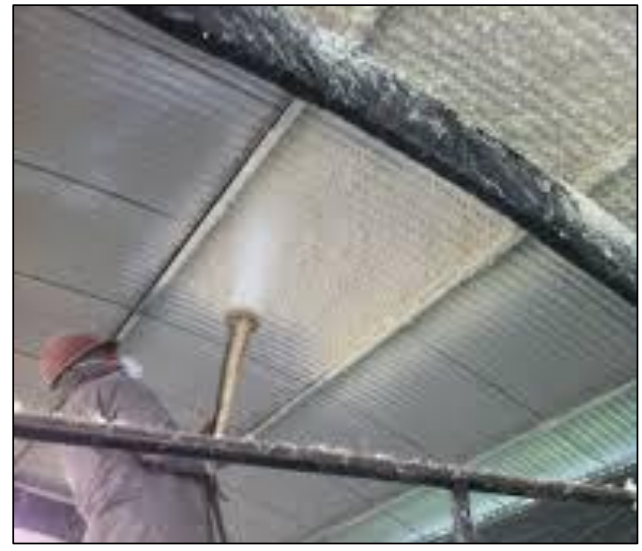

Figure 7: Sandblasted glass wool. Source: [10].

Rock wool, shown in Figure 8, this material is obtained by melting different types of rock at a temperature of about $1500^{\circ} \mathrm{C}$ to obtain the fibers that are bonded by a resin to form a blanket or panel, this material is not fuel [10].

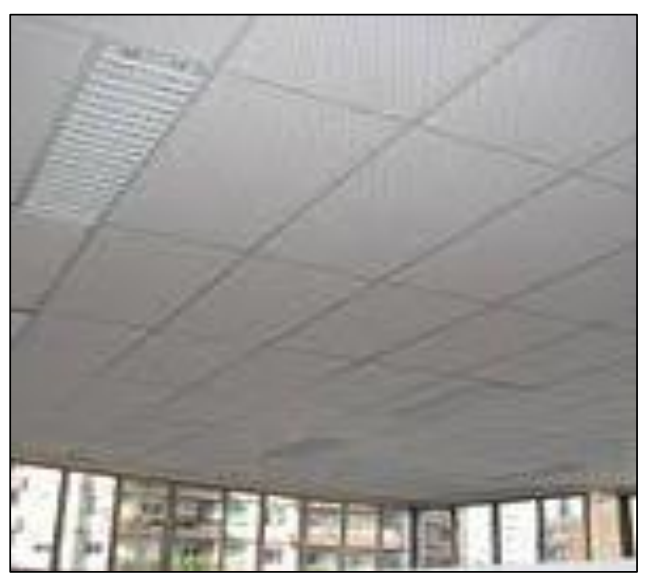

Figure 8: Rock wool panels.

Source: [10]. 


\section{DEVELOPMENT}

This case study was developed in the Product Testing Sector of a motorcycle industry at the Manaus Industrial Pole in 2019.

The methodological procedure is divided into two main parts: the noise level mapping; and the development of the proposed acoustic booth, as shown in Figure 9.

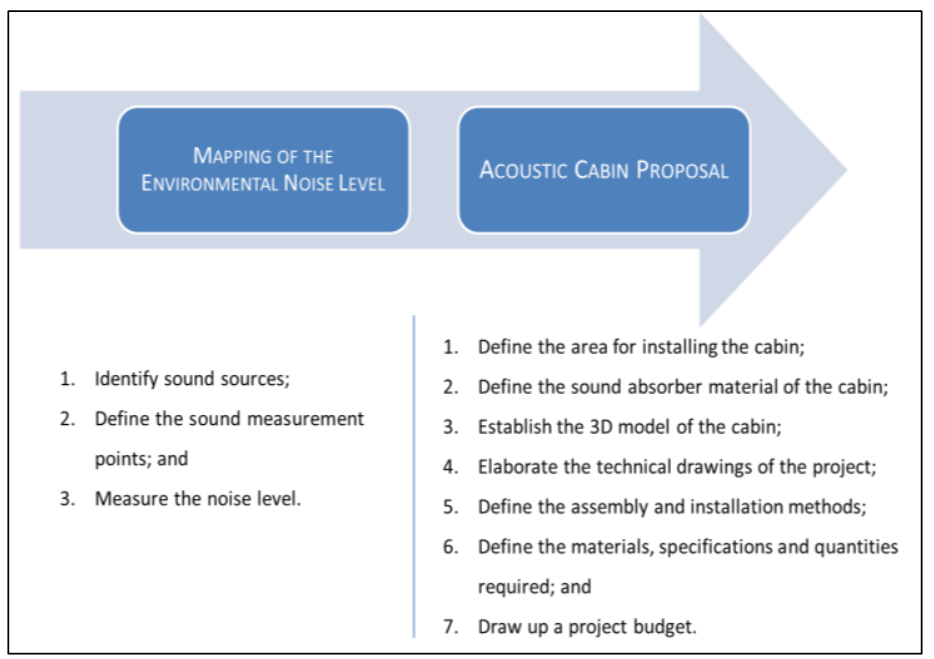

Figure 9: Steps of the methodological procedure. Source: Authors, (2019).

\section{III.1 MAPPING THE ENVIRONMENTAL NOISE LEVEL}

The sound sources in the testing area were related through on-site verification.

The sound sources identified were:

- 7 industrial fans;

- 3 motorcycle test equipment (dynamometers);

- the motorcycle engine;

- the motorcycle horn.

The positioning of the sound sources found is as indicated in the layout of Figure 10.

The noise level measurement points were defined by observing the places of passage of employees and between the listed sound sources.

9 measurement points were defined in the motorcycle testing sector, according to the layout in Figure 10. Between points 1,2 , and 3 is 5 meters apart, between the other points is 2 meters and approximate height of $1.5 \mathrm{~m}$ (corresponding to the human ear according to NR 15 [15]).

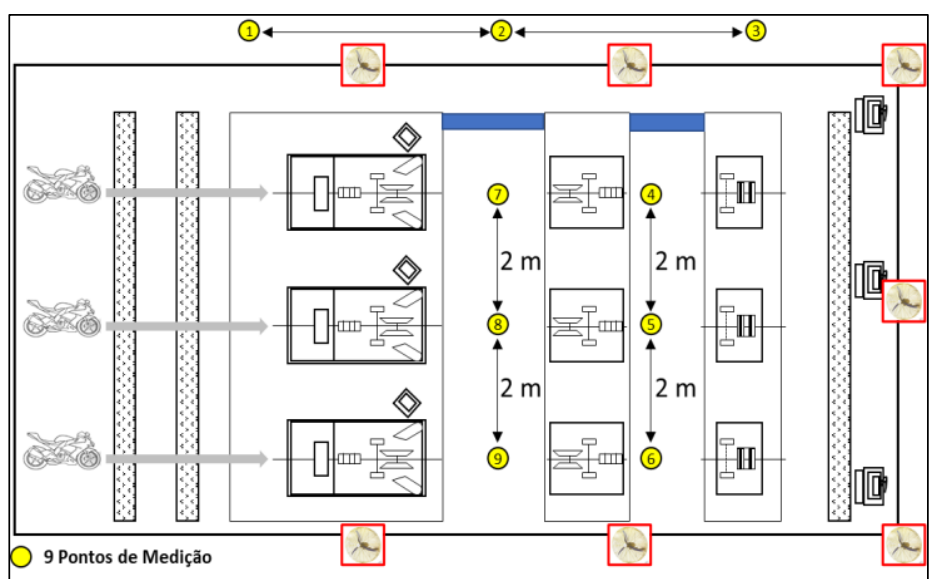

Figure 10: Sound pressure level measurement sources and points. Source: Authors, (2019).
The noise level was measured at each defined point, using the sound pressure measurement instrument of the manufacturer Brüel \& Kjaer, as shown in Figure 11. The instrument is calibrated and has a valid certificate giving reliability to the measurement performed.

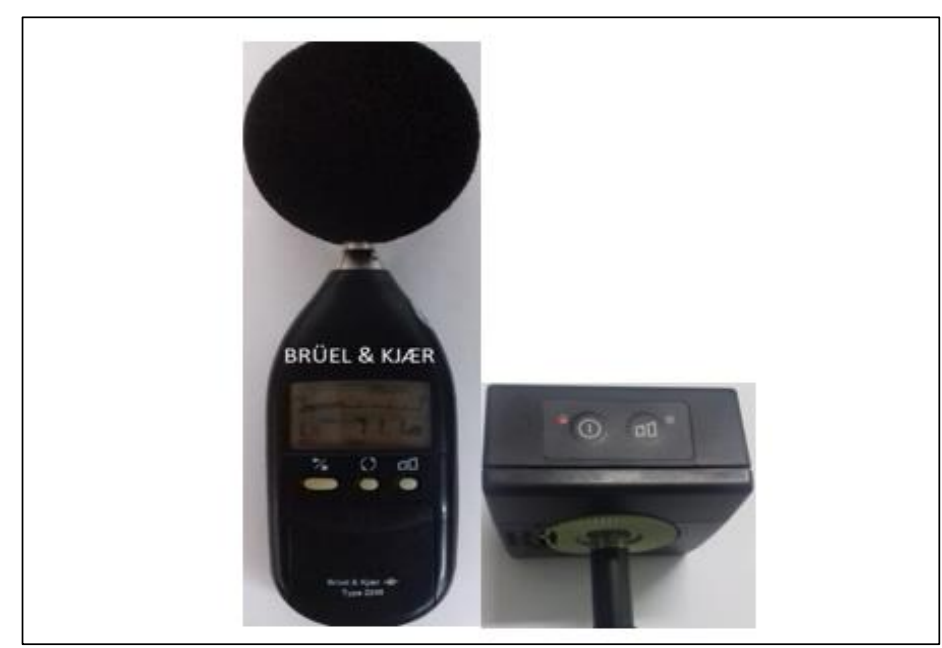

Figure 11: Sound pressure gauge (left side). Verification of the sound pressure gauge measurement (right side). Source: Authors, (2019).

The sound pressure meter has: 1) a windshield as shown in Figure 11, so that the action of the wind does not interfere with the capture of sound vibrations; 2) a microphone as shown in Figure 11, responsible for capturing the sound vibrations and transforming it into an electrical signal as a result of the decibel measurement; and 3) a calibrator was used before the measurements started.

The measurement of the pressure gauge was done in two steps, in the first the first level was selected, which is $94.01 \pm 0.2$ $\mathrm{dB}$, the microphone was directly coupled to the calibrator as shown in Figure 11 (right side) and the result was $94.1 \mathrm{~dB}$, in the second measurement step the second level was selected, which is $114.02 \pm$ $0.2 \mathrm{~dB}$, the result of $114.0 \mathrm{~dB}$ was found. With the results within the tolerance limit, the sound pressure meter is as specified, being able to consider the measurements valid.

With the sound pressure meter properly measured, 36 measurements were made, distributed in 9 points defined in Figure 10 (points of passage of people in the sector). The measurements are shown in Table 3 and in the graph of Figure 12. The normative reference value of NR 15 [15] of $85 \mathrm{~dB}$ is identified in Figure 12 by the blue dotted line. The noise levels presented in Table 3 were measured progressively and cumulatively from the 7 fans, 3 test equipment, 3 engines and 3 horns of the motorcycles under test. The test area is closed, in the same environment in continuity with the final assembly line of the motorcycles.

Table 3: Sound pressure level measurements at each point $(\mathrm{dB})$.

\begin{tabular}{|c|c|c|c|c|}
\hline $\begin{array}{c}\text { Sound } \\
\text { source }\end{array}$ & $\begin{array}{c}\text { Motorcycle } \\
\text { horn }\end{array}$ & $\begin{array}{c}\text { Motorcycle } \\
\text { engine }\end{array}$ & Test Equipment & $\begin{array}{c}\text { Industrial } \\
\text { fan }\end{array}$ \\
\hline Point 1 & 98.4 & 91.3 & 78.1 & 73.2 \\
\hline Point 2 & 101.1 & 90.6 & 81.2 & 75.0 \\
\hline Point 3 & 97.3 & 88.9 & 77.9 & 76.5 \\
\hline Point 4 & 102.2 & 89.9 & 78.3 & 76.1 \\
\hline Point 5 & 101.4 & 88.2 & 77.8 & 71.0 \\
\hline Point 6 & 100.4 & 89.8 & 79.0 & 74.7 \\
\hline Point 7 & 102.3 & 92.3 & 80.5 & 73.4 \\
\hline Point 8 & 103.0 & 92.3 & 80.2 & 72.3 \\
\hline Point 9 & 102.1 & 90.1 & 81.1 & 78.8 \\
\hline Average & 100.91 & 90.38 & 79.34 & 74.56 \\
\hline
\end{tabular}

Source: Authors, (2019). 


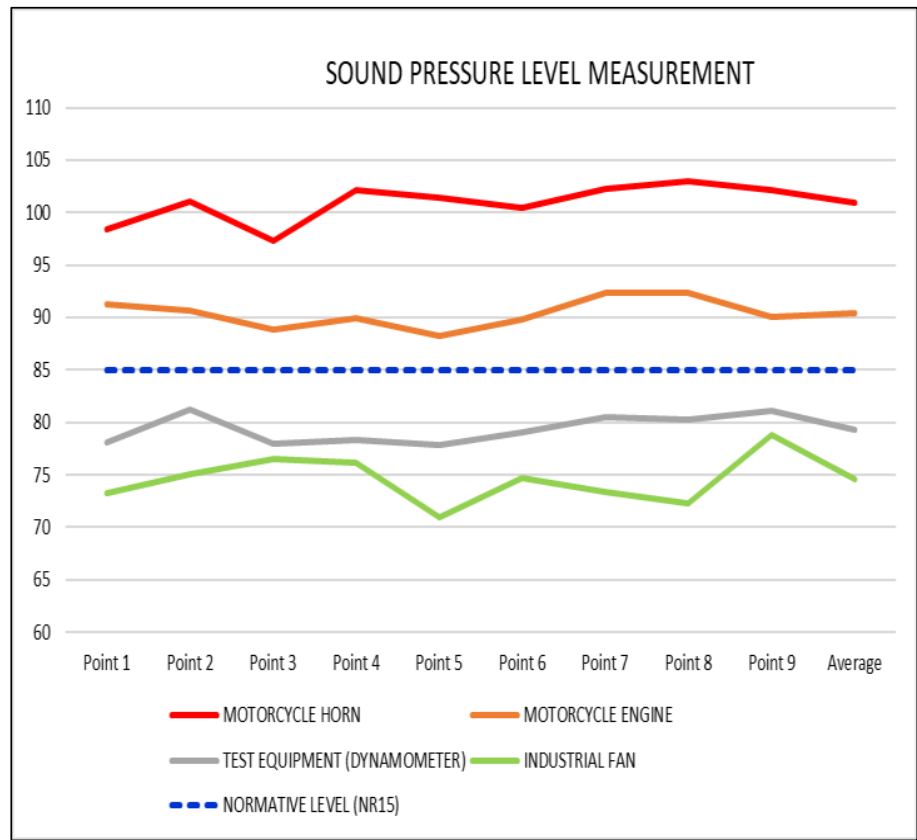

Figure 12: Graph of sound pressure measurements. Source: Authors, (2019).

\section{III.2 ACOUSTIC BOOTH PROPOSAL}

The test site, necessary for the installation of the acoustic booth, was evaluated. Possible interferences, accesses and modifications were observed.

The project sought to adapt to the available area and perimeter so that significant changes were not necessary. So, the available area is $28.5 \mathrm{~m} 2$, as shown in Figure 13. With an available height of $3 \mathrm{~m}$, up to the luminaires, therefore, the final dimension is $3800 \mathrm{~mm} \times 7500 \mathrm{~mm} \times 3000 \mathrm{~mm}$. This space comprises 3 simultaneous test equipment as shown in Figure 13.

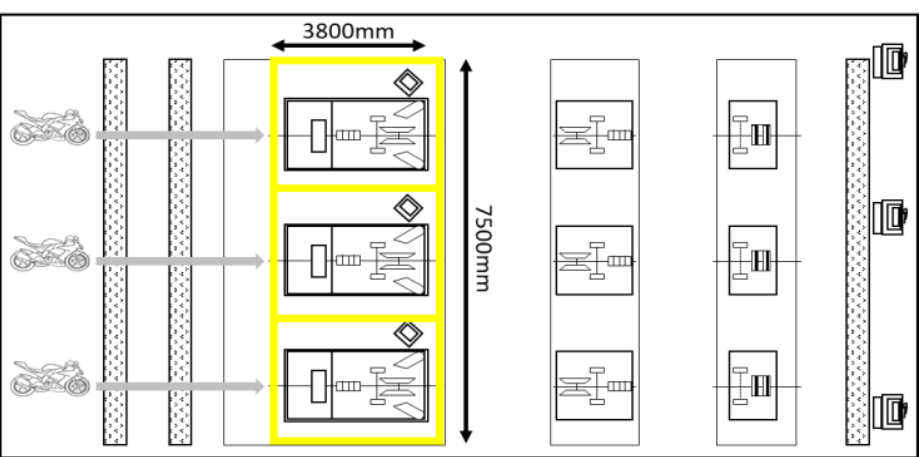

Figure 13: Location of the acoustic booth. Source: Authors, (2019).

Decision is a choice between several alternatives and the decision-making process is a form of structuring the problem that aims to identify the best options. This structure must be constructed in stages, including problem definition, identification of alternatives, definition of criteria/objectives and their weights, and finally determine the best alternative [18]. The material alternatives with the highest potential for available and recommended sound absorbers (polyurethane foam; glass wool; and rock wool - Figures 6, 7 and 8 respectively) were compared in the Matrix of Table 4. The comparison criteria, among the indicated materials were: the sound absorption coefficient; resistance to temperature; the cost of the square meter; the useful life; maintainability; and availability in the national market. The weights and grades assigned to each material were recommended by a multidisciplinary team in the areas of projects, maintenance, quality, safety and purchases.

The criteria weights were established hierarchically from the most important (weight 7) to the least important (weight 2). Similarly, the comparison between the 3 material options, within each criterion, was hierarchically defined from the best evaluated (value $=4$ ) to the least evaluated (value $=2$ ). The criterion total is the product between the criterion weight and the value. The grand total is the sum of the total of all criteria.

The comparison matrix in Table 4 presents the evaluation and the results of the comparison, with rock wool being best evaluated.

Table 4: Evaluation matrix for sound absorbing materials.

\begin{tabular}{|c|c|c|c|c|c|c|c|c|c|}
\hline \multicolumn{2}{|c|}{ COMPARISON MATRIX } \\
EVALUATION OF THE SOUND \\
ABSORBING MATERIAL OF THE \\
ACOUSTIC CABIN
\end{tabular}

Source: Authors, (2019).

A 3D acoustic booth was modeled using the Auto CAD software. The cabin has 3 doors at the front (entrance) and 3 at the rear (exit), for entry and exit of the test equipment motorcycles, as shown in Figure 14. The dimensions in detail are shown in the 2D drawings of Figures 15, 16, 17, 18 and 19 (measures in mm). 


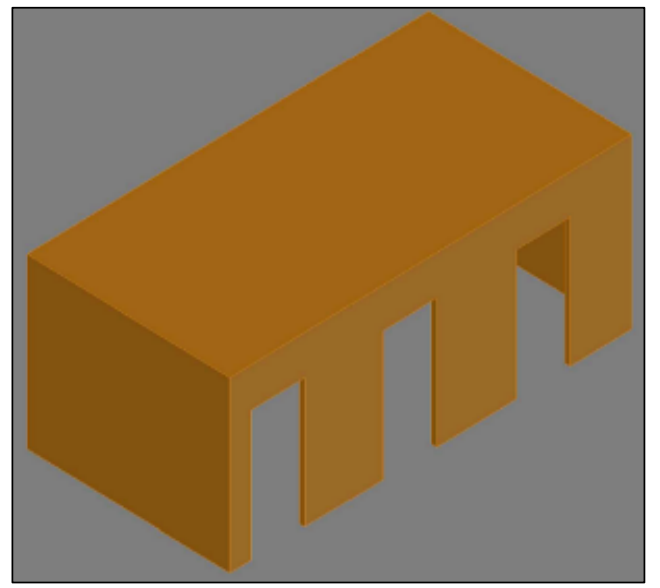

Figure 14: Acoustic cabin layout. Source: Authors, (2019).

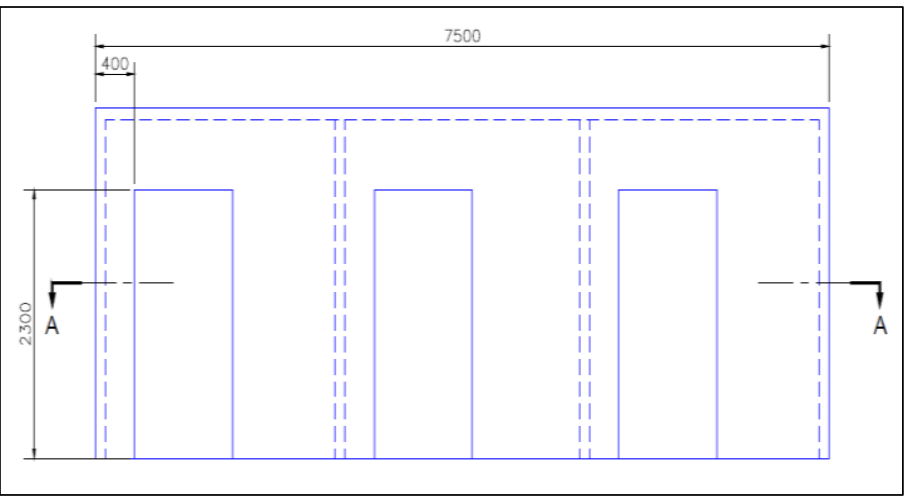

Figure 15: Front view, with the divisions between the 3 test equipment.

Source: Authors, (2019).

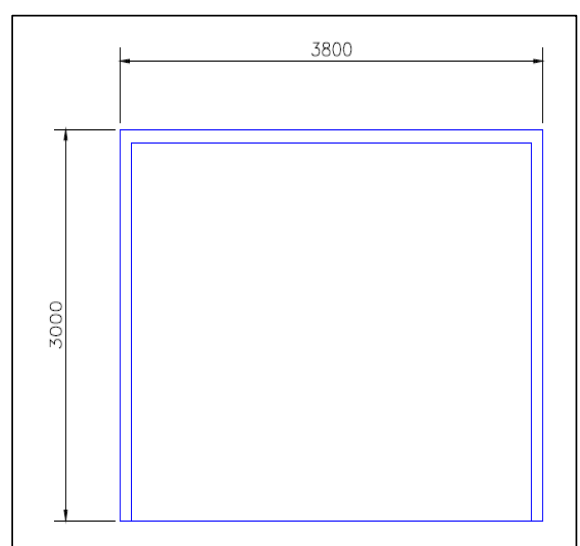

Figure 16: Left side view.

Source: Authors, (2019).

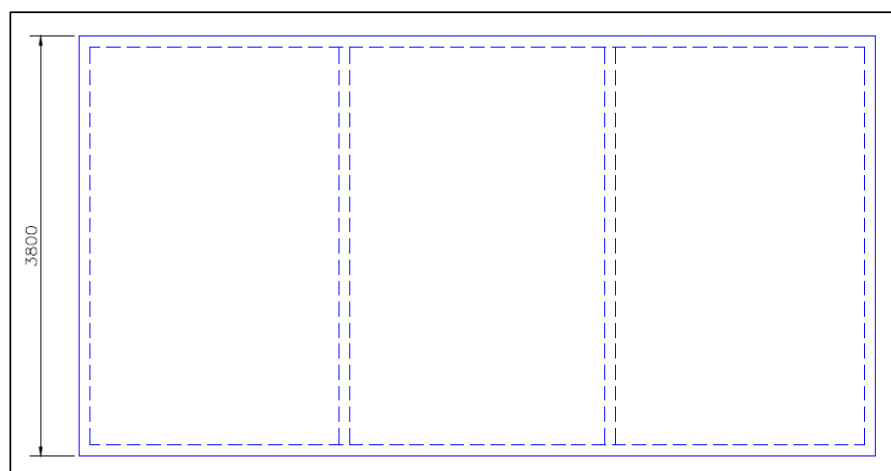

Figure 17: Top view. Source: Authors, (2019).
Section A-A of Figure 15 shows the detail of the automated sliding doors that close and open automatically at the beginning and end of the test, respectively.

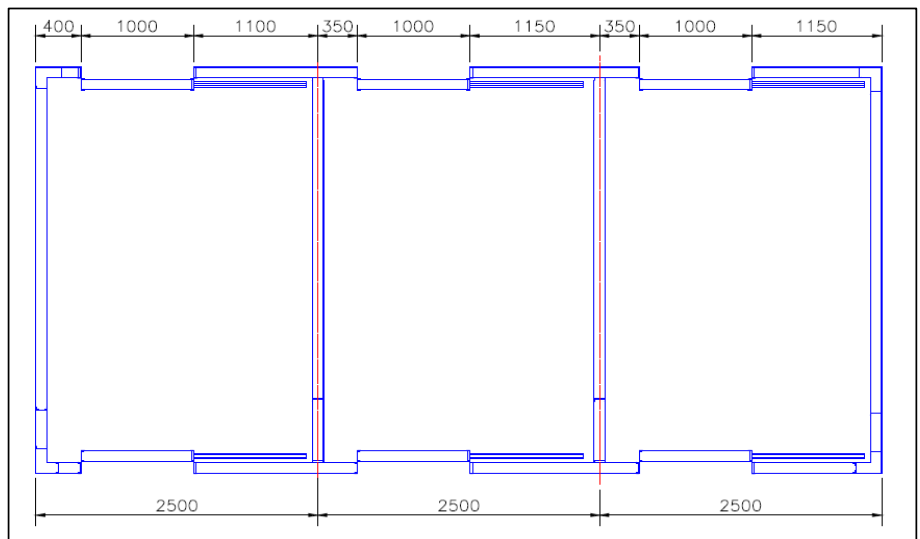

Figure 18: Section A-A (doors closed during testing). Source: Authors, (2019).

The details of the constructive configuration, including the assembly, of the panels are presented through Figures 19, 20 and 21. The cabin consists of panels of $3 \mathrm{~m}$ by $3 \mathrm{~m}$ (total thickness of $100 \mathrm{~mm}$ ), coated on both sides by steel sheets of $1.2 \mathrm{~mm}$ thick and filled internally with the selected sound absorbing material (rock wool).

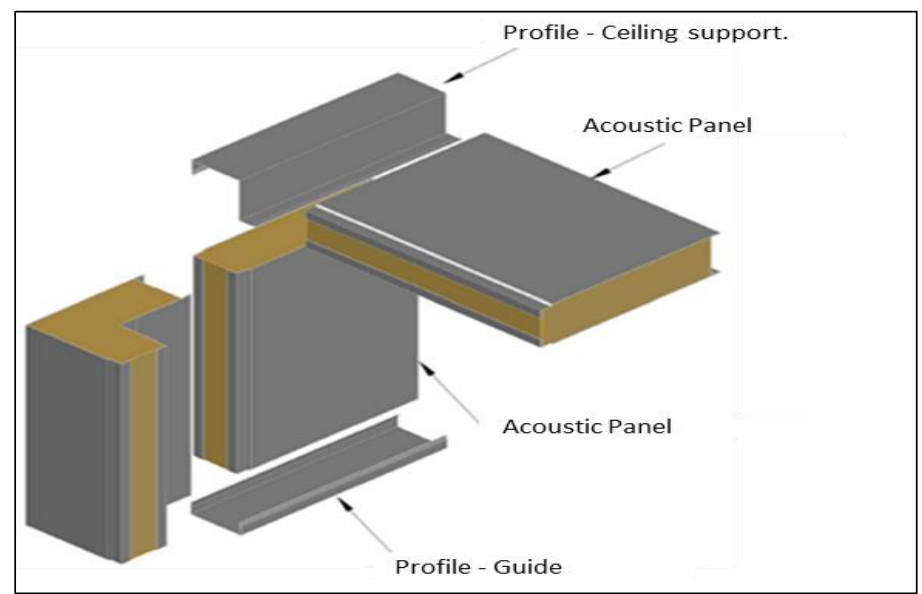

Figure 19: Construction and assembly details of the cabin panels. Source: Authors, (2019).

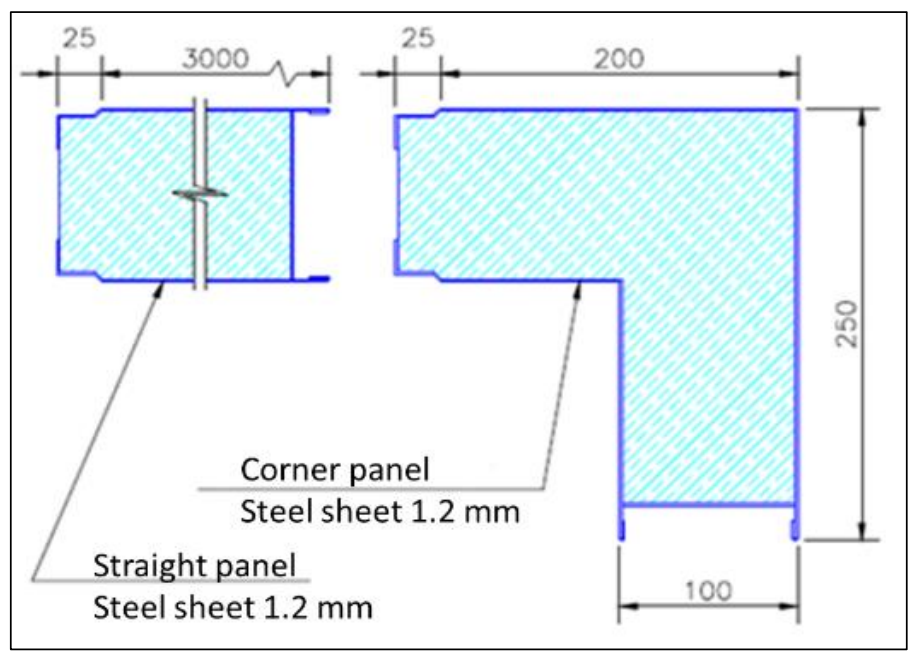

Figure 20: Constructive, dimensional and assembly details of the panels.

Source: Authors, (2019). 
The steel plates of the cabin's internal panels have holes for the flow of sound energy (noise). This configuration improves the absorption of noise in the cabin (prevents sound reverberation - noise return). The schematic of the distribution and size of the holes is shown in Figure 21.

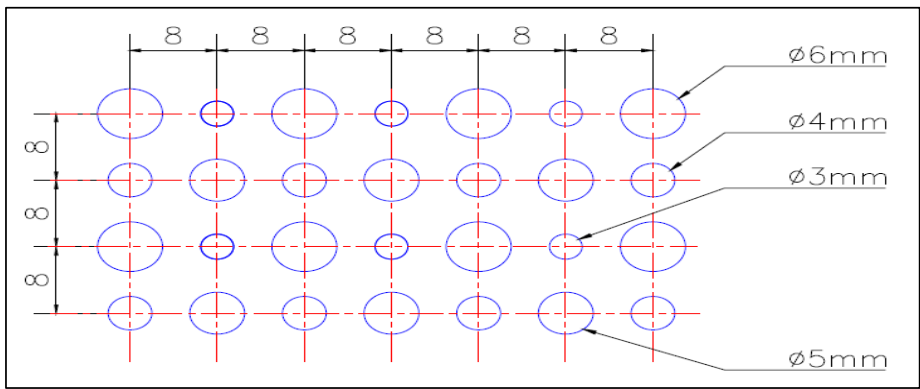

Figure 21: Scheme of distribution and dimension of the holes in the internal plate of the panel.

Source: Authors, (2019).

The Table 5 presents the project's bill of materials, describing specifications and quantities.

Table 5: Project's bill of materials.

\begin{tabular}{|c|c|c|c|c|}
\hline KIT & IT & DESCRIPTION/MATERIAL & TECHNICAL SPECIFICATIONS & QUANTITY \\
\hline \multirow{3}{*}{$\begin{array}{l}\text { STEEL PANEL WITH ROCK WOOL } \\
\text { NUCLEUS }\end{array}$} & 01 & SMOTHPLATE & GALVANIZED STEEL, $1.2 \mathrm{~mm}$ THICKNESS. & $96.3 \mathrm{~m}^{2}$ \\
\hline & 02 & PERFORATED PLATE & GALVANIZED STEEL, $1.2 \mathrm{~mm}$ THICKNESS. & $141.9 \mathrm{~m}^{2}$ \\
\hline & 03 & $\begin{array}{l}\text { ACOUSTIC INSULATION } \\
\text { OF ROCK WOOL }\end{array}$ & DENSITY OF $80 \mathrm{~kg} / \mathrm{m}^{3}$ & $11.91 \mathrm{~m}^{3}$ \\
\hline \multirow{2}{*}{$\begin{array}{c}\text { SUPPORT STRUCTURE FOR } \\
\text { ASSEMBLY }\end{array}$} & 04 & "U" PROFILE - GUIDE & $\begin{array}{l}\text { CARBON STEEL 1020, HOT GALVANIZED, } 101.6 \\
\text { mm SOUL, } 4.67 \mathrm{~mm} \text { THICKNESS. }\end{array}$ & $30.2 \mathrm{~m}$ \\
\hline & 05 & $\begin{array}{l}\text { PROFILE - CEILING } \\
\text { SUPPORT }\end{array}$ & $\begin{array}{l}\text { CARBON STEEL 1020, HOT GALVANIZED, } 101.6 \\
\text { mm SOUL, } 4.67 \mathrm{~mm} \text { THICKNESS. }\end{array}$ & $30.2 \mathrm{~m}$ \\
\hline \multirow{4}{*}{ SUPPORT STRUCTURE FOR FIXING } & 06 & SLIDING DOOR GUIDE & $\begin{array}{c}\text { SLIDING CAR OF STEEL, WITH TWO PULLEYS } \\
\text { AND WITH BRAKE. }\end{array}$ & 12 unit \\
\hline & 07 & SLIDING DOOR RAIL & $\begin{array}{l}\text { STEEL 1045, EXTRUDED. } \\
\end{array}$ & $12.6 \mathrm{~m}$ \\
\hline & 08 & FIXING SCREW - GUIDE & $\begin{array}{l}\text { SELF-DRILLING / LAMINATED STEEL / ZINCED } \\
\text { SURFACE. }\end{array}$ & 76 unit \\
\hline & 09 & $\begin{array}{l}\text { FIXING SCREW - SIDES } \\
\text { AND CEILING } \\
\end{array}$ & $\begin{array}{l}\text { SELF-DRILLING / LAMINATED STEEL / ZINCED } \\
\text { SURFACE. }\end{array}$ & 220 unit \\
\hline
\end{tabular}

Source: Authors, (2019).

A price and budget survey was carried out with national suppliers, according to the bill of materials in Table 5. Table 6 presents the lowest value budget.

Table 6: Budget of the acoustic booth.

\begin{tabular}{|l|l|c|r|r|r|}
\hline It & \multicolumn{1}{|c|}{ Description } & Unit & Quantity & \multicolumn{1}{c|}{ Price } & Total (R\$) \\
\hline 01 & $\begin{array}{l}\text { Steel panel with rock } \\
\text { wool core. }\end{array}$ & $\mathrm{m}^{2}$ & 119.1 & 242.46 & 28876.99 \\
\hline 02 & Profile - Guide. & $\mathrm{m}$ & 30.2 & 65.46 & 1976.89 \\
\hline 03 & Profile - Ceiling support. & $\mathrm{m}$ & 30.2 & 44.45 & 1342.39 \\
\hline 04 & Guide for sliding door. & unit & 12 & 65.8 & 789.60 \\
\hline 05 & Rail for sliding door. & $\mathrm{m}$ & 12.6 & 17.91 & 225.67 \\
\hline 06 & Fixing screw - Guide. & unit & 76 & 2.49 & 189.24 \\
\hline 07 & $\begin{array}{l}\text { Fixing screw - Walls and } \\
\text { ceiling. }\end{array}$ & unit & 220 & 0.38 & 83.60 \\
\hline
\end{tabular}

Source: Authors, (2019).

\section{RESULTS AND DISCUSSIONS}

The results of the work are listed below in accordance with the research objectives and the methodology:

The sound sources were identified and listed: Industrial fans; Test Equipment; motorcycle engine; and motorcycle horn;

Nine (9) noise measurement points, in the current layout of the motorcycle test area, were indicated considering the flow of people on these routes exposed to noise;

Thirty-six noise level measurements were made distributed over the 9 defined points. The motorcycle horn promoted the highest sound pressure level at $100.9 \mathrm{~dB}$.

The installation area of the cabin was defined and delimited, comprising 3 test equipment simultaneously, without the need for significant changes or modifications of the location;
The sound absorbing material of the cabin was selected based on 6 comparison criteria. Rock wool stood out in the evaluation, being the material indicated as a sound absorber; and

The constructive, geometric and assembly specifications were defined, modeled and issued technical drawings. As well as, the project bill of materials and respective budget in the amount of $\mathrm{R} \$ 33484.37$.

This design can be applied to any noisy area, requiring only dimensional adjustments of the cabin.

\section{CONCLUSIONS}

The research objectives of mapping the sectorial noise level and establishing a proposal for an acoustic booth in the test process, which reduced the level of noise exposure of people traveling in this area were achieved. It is estimated that the level of environmental noise should be reduced between $40 \mathrm{~dB}$ and $50 \mathrm{~dB}$ with the implementation of the acoustic cabin in the test equipment. The greatest risk is related to employees in administrative areas who travel near the test areas without the use of hearing protection or who remain for a long period in this traffic. The hearing protector reduces noise intensity by about $15 \%$, leaving acceptable levels for 8 hours of exposure. As well, considering the analysis of NR15, the mapped levels are acceptable up to 30 minutes of exposure. Process employees wear ear protectors. However, the cabin also promotes improvements in the inspection process allowing the inspector to concentrate on the noise inherent in the inspected motorcycle. It minimizes that the inspector hears noises from other motorcycles, environmental or sound reverberation. Furthermore, the lower the level of environmental noise, the more pleasant for people and productive for the company. In future works it is proposed to implement the acoustic booth, a new noise 
mapping, comparison of productivity, quality and satisfaction of the people who work and travel through the test area.

\section{REFERENCES}

[1] P. Roelofsen, "Evaluation of environmental noise based upon the percentage of dissatisfied," J. Facil. Manag., vol. 10, no. 2, pp. 133-139, Apr. 2012.

[2] A. Czyzewski and J. Kotus, "Universal system for diagnosing environmental noise," Manag. Environ. Qual. An Int. J., vol. 15, no. 3, pp. 294-305, 2004.

[3] A. Essien, Sound Sources: The Origin of Auditory Sensations, 1a ed. New York, NY: Michael Terence, 2019.

[4] R. Kumar, E. Madhu, A. Maan, S. Sinha, and N. Akhtar, "Estimation of combined exposure factor due to the impact of different transport related environmental pollutants air quality and noise level in Delhi city," World J. Sci. Technol. Sustain. Dev., vol. 12, no. 4, pp. 269-280, Oct. 2015.

[5] M. N. K. Saunders, P. Lewis, and A. Thornhill, Research methods for business students. Prentice Hall, 2009.

[6] J. A. Sharp, J. Peters, and K. Howard, The management of a student research project. Gower, 2002.

[7] P. Montanari, V.; Cunha, Nas ondas do som. São Paulo-SP: Moderna, 1996.

[8] R. F. Barron, Noise Control and Acoustics, 1a ed. Columbus, OH: CRC Press, 2003.

[9] S. R. Bistafa, Acústica aplicada ao controle do ruído. São PauloSP: Blücher, 2018.

[10] S. Gerges, Ruído: Fundamentos e Controle, Ed. 2a. Florianópolis-SC: NR Editora, 2000.

[11] L. A. Nepomuceno, Elementos de acústica física e psicoacústica. São Paulo-SP: Edigard Blücher, 1994.

[12] S. Gerges, Ruídos e vibrações veiculares, 1a ed. FlorianópolisSC: NR Editora, 2005.

[13] T. Ford, "Test improves accuracy of acoustic aircraft cabin model," Aircr. Eng. Aerosp. Technol., vol. 76, no. 6, pp. 284-289, Dec. 2004.

[14] A. A. Nudelmann, E. A. da. Costa, J. Seligman, and R. N. Ibañez, PAIR: perda auditiva induzida pelo ruído. Porto AlegreRS: Revinter, 2001.

[15] BRASIL, Norma Regulamentadora do Ministério do Trabalho. NR 15 - Atividades e Operações Insalubres. BRASIL, 1978.

[16] "High-performance thermal and acoustic protection," Aircr. Eng. Aerosp. Technol., vol. 73, no. 1, pp. 93-100, Feb. 2001.

[17] "Researchers can reduce noise in aircraft cabins with 'active' trim panels," Aircr. Eng. Aerosp. Technol., vol. 80, no. 3, pp. 2728, May 2008.
[18] J. C. Soares, S. D. Sousa, and A. Tereso, "A decision-making model for the rework of defective products," Int. J. Qual. Reliab. Manag, 2019. 